\title{
$\mathfrak{I} \mathfrak{i} \mathfrak{b} \mathfrak{a} \mathfrak{l} \mathfrak{t}$.
}

\section{Griteß seft.}

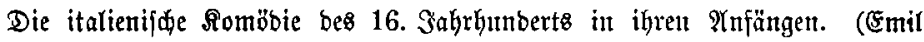
Fetrerlein.) . . . . . . . . . . . . . . . . Seite 1

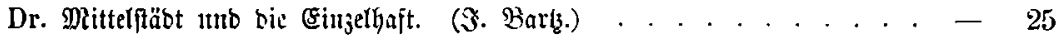

Die Deutfdenbetze in ungarn. (Üus ungarn.) . . . . . . . . . . . . - 41

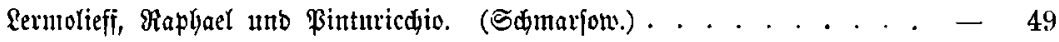

Die Reitutg bes Manïbers. . . . . . . . . . . . . . . . . . -57

(Buftav Frentag's alynen. (Sulian Sdumibt.) . . . . . . . . . . . - 65

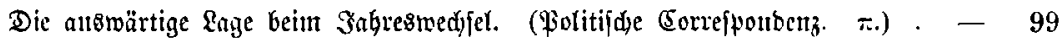

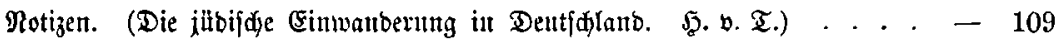

\section{3weitez̧ seft.}

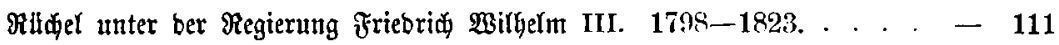

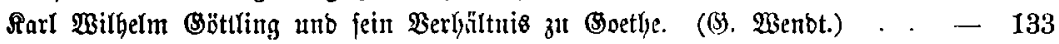

Die Selfipermaltumg im Sormundfifajtsedft. (Dr. Rofffa.) . . . . . . -143

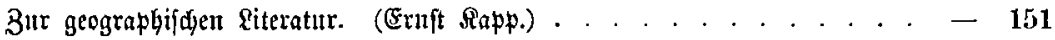

Seffing. 15. Februar 1881. (Yutlian Sdmitt.). . . . . . . . . . - 161

\$ermann \&oz̧e. (Şugo Sommer.) . . . . . . . . . . . . . . . . -177

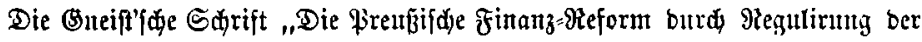

(5emeinbe=Steuern unb ber Sommunalftenter \&ejetzentrourf“. (Bon einem

Mitgliebe bes $\mathfrak{A G g e o r b n e t e n g a n l e s . ) ~ . ~ . ~ . ~ . ~ . ~ . ~ . ~ . ~ . ~ . ~ . ~ . ~ . ~ . ~ . ~}-196$

\section{Drittę $\mathfrak{g e f t}$.}

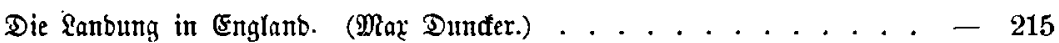

Die irifde Eanbfrage. (Enbwig Freiberr vou Dmpteta.) . . . . . . . . 242

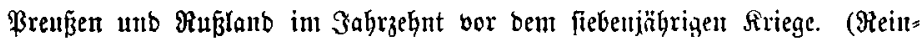

Golb Rofer.) . . . . . . . . . . . . . . . . . -285

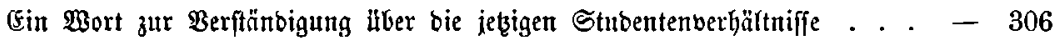

Notizen. . . . . . . . . . . . . . . . . -312 


\section{Bicrtez Sejt.}

Fiorenza. (5erman (Grimm.) . . . . . . . . . . . . . Seite 319

Die irifde Eanbfrage. (Enbmig freiberr bon Smptera.) (Sdluß.). . . . - 361

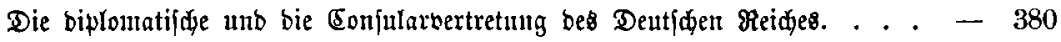

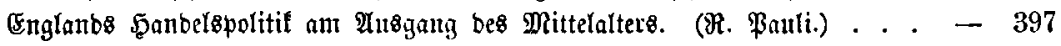

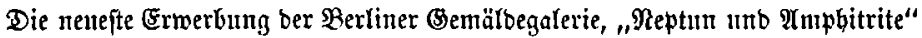

vont \$. B. 9uubent. (BBobe.) . . . . . . . . . . . . . . - 420

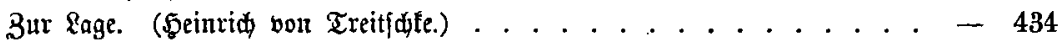

Notizen. ................... . . 444

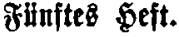

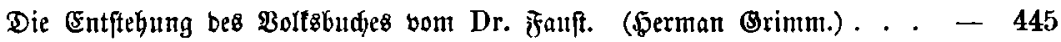

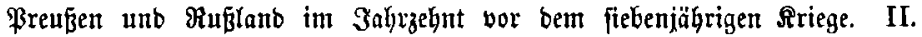

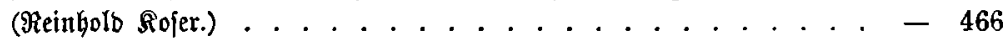

Irtöfterreidifde (Eulturbilber. II. (EGriftian Mener.) . . . . . . . -494

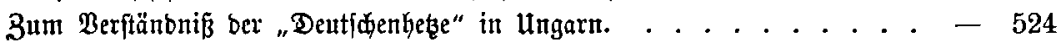

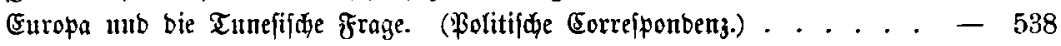

\section{Sediftę 5 eft.}

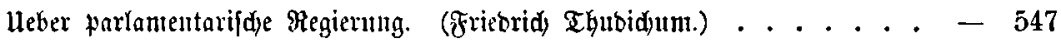

Sädfif

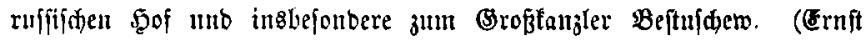
Sgerrmant.) . . . . . . . . . . . . . . -558

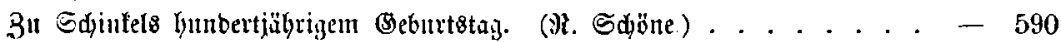

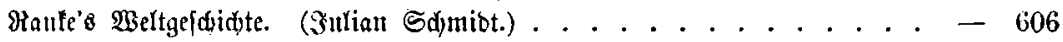

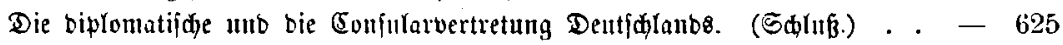

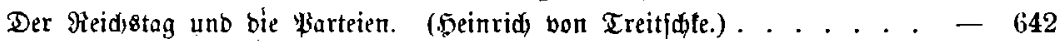

